\title{
Fabrication of Tungsten Carbide Films by Filtered Pulse Arc Deposition with Cemented Tungsten Carbide Cathodes
}

\author{
Ryo Isono ${ }^{1}$, Tsuyoshi Tanimoto ${ }^{*}$, Yushi Iijima1, Toru Harigai ${ }^{1}$, Yoshiyuki Suda1, \\ Hirofumi Takikawa', Satoru Kaneko ${ }^{2}$ \\ ${ }^{1}$ Toyohashi University of Technology, Aichi, Japan \\ ${ }^{2}$ Kanagawa Institute of Industrial Science and Technology, Kanagawa, Japan \\ Email: *tanimoto@ee.tut.ac.jp
}

How to cite this paper: Isono, R., Tanimoto, T., Iijima, Y., Harigai, T., Suda, Y., Takikawa, H. and Kaneko, S. (2017) Fabrication of Tungsten Carbide Films by Filtered Pulse Arc Deposition with Cemented Tungsten Carbide Cathodes. Materials Sciences and Applications, 8, 966-978. https://doi.org/10.4236/msa.2017.813071

Received: October 28, 2017

Accepted: December 5, 2017

Published: December 8, 2017

Copyright $\odot 2017$ by authors and Scientific Research Publishing Inc. This work is licensed under the Creative Commons Attribution International License (CC BY 4.0). http://creativecommons.org/licenses/by/4.0/

\begin{abstract}
Tungsten carbide films (W-C films) were fabricated on silicon substrates by using the filtered pulse arc deposition (FPAD) method. Two types of cemented tungsten carbide (WC) were used as cathode, one containing Co and the other $\mathrm{Ti}$, which were used as binders for forming the cathode shape. The films were fabricated by varying the pulse arc current and substrate bias voltage. The discharge, deposition and film properties were investigated under these deposition conditions. The cathode wear amount when using WC-Co (WC cathode containing Co) was found to be smaller than that measured when WC-Ti (WC cathode containing $\mathrm{Ti}$ ) was used. The $\mathrm{W}-\mathrm{C}$ film thickness was approximately $30-40 \mathrm{~nm}$ under all conditions, except when the pulse arc current was $50 \mathrm{~A}$ and the film thickness, was approximately $10 \mathrm{~nm}$. Compared to the WC-Ti, the consumption of cathode material is suppressed in the WC-Co, indicating that the efficiency for film preparation of the latter is good. From the X-ray diffraction analysis, the crystalline phase of $\mathrm{W}-\mathrm{C}$ films fabricated using WC-Co and WC-Ti were observed as $\mathrm{W}_{2} \mathrm{C}$ and $\mathrm{WC}_{1-\mathrm{x}}$, respectively, indicating that different crystalline phases could be fabricated using different cathodes. From the X-ray photoelectron spectroscopy analysis, the oxidation layer formed by air exposure was observed to exclusively exist on the $\mathrm{W}-\mathrm{C}$ film surface. Moreover, almost all oxygen in the oxidation layer bonded with tungsten.
\end{abstract}

\section{Keywords}

Cemented Tungsten Carbide Cathode, Thin Film, Filtered Pulse Arc Deposition 


\section{Introduction}

Cemented tungsten carbide (WC) exhibits excellent material properties such as high mechanical hardness, wear resistance, high melting point, chemical inertness, electrical conductivity, and low friction coefficient. It is often used as the base material for cutting and molding tools [1] [2] [3]. Tungsten carbide films (W-C films) have also been used as surface protection films for wear resistance improvement [4] [5]. Additionally, the use of W-C film as an interlayer between a substrate and diamond-like carbon (DLC) film or diamond film has been anticipated. As an interlayer, it improves the adhesion of the DLC film or diamond film on the substrate [6] [7] [8] [9].

The deposition method of $\mathrm{W}-\mathrm{C}$ films is categorized either as chemical vapor deposition (CVD) or physical vapor deposition (PVD). In the thermal CVD method, a W-C film is deposited by heating a substrate to approximately $1000^{\circ} \mathrm{C}$ in a gaseous mixture atmosphere of $\mathrm{WCl}_{6}$ and hydrocarbon [10]. In the sputtering method, which is the most commonly used PVD method, a W-C film is fabricated by heating a substrate to several $100^{\circ} \mathrm{C}$ [11] [12]. The target is tungsten or WC, and the atmosphere gas is Ar gas or a mixture of Ar and hydrocarbon. The films deposited using the CVD and sputtering methods often present crystalline structures of $\mathrm{W}_{2} \mathrm{C}$ and $\mathrm{WC}_{1-\mathrm{x}}$. In this regard, the reported observations of the WC phase are less than those of $\mathrm{W}_{2} \mathrm{C}$ or $\mathrm{WC}_{1-\mathrm{x}}$ [13] [14] [15] [16].

In addition to the sputtering method, the PVD method also includes the cathodic vacuum arc deposition (CVAD) method [17] [18]. In the CVAD method, a solid material is used as cathode, which acts as an evaporation source. The cathode material evaporates at a cathode spot, which is very active and has high temperatures when formed by an arc discharge [19]. Because the amount of ion in the plasma is large and ion energy is high, the CVAD method makes it possible to deposit films having a different film quality from that produced through the conventional sputtering method. However, in the CVAD method, the cathode spot also emits electrically neutral micron-sized fine particles (called droplets). Droplets in a film significantly decrease the film properties such as surface flatness and mechanical hardness [20]. As a method of reducing droplets in a film, the filtered arc deposition (FAD) method can be employed [21] [22]. In the FAD method, the charged particles and droplets generated from the cathode are separated and transported to the substrate by the equipped magnetic field, consequently producing high-quality films free from droplets.

Periodic arc discharge occurs and the plasma is generated in the filtered pulse arc deposition (FPAD) method [23] [24]. The FPAD method has the following features in comparison with the DC arc deposition method. The FPAD method operates at a low average power so that temperature rise around the cathode is suppressed. Under the method, the evaporation material size becomes compact. Moreover, material difficult to discharge in the DC arc deposition method can be used the cathode [25] [26]. Therefore, the FPAD method can be regarded as a powerful evaporation method for developing new materials. 
In this study, W-C films were fabricated on Si substrates by using the FPAD method. We used two types of WCs as cathode, one containing Co and the other $\mathrm{Ti}$, which were used as binders for forming the cathode shape. The W-C films were fabricated by varying the pulse arc current and substrate bias voltage.

\section{Experimental Details}

The experiments were performed using the FPAD system [27]. This system consists of a focus coil and a $90^{\circ}$ torus filter coil in order to transfer the plasma beam to the substrate. The droplets, which degenerate film quality, are removed by this filter coil [28] [29]. The substrate material used was Si (100), and it was fixed to the substrate table by using carbon double-stick tapes. The WCs which contain either $\mathrm{Co}$ or $\mathrm{Ti}$ as binder for forming the cathode shape, were used in the cathode. The binder contents of WC-Co (WC cathode containing Co) and WC-Ti (WC cathode containing Ti) are approximately $5 \mathrm{wt} \%$ and $1 \mathrm{wt} \%$, respectively. The pulse arc currents are 50,100, and $150 \mathrm{~A}$, and the pulse frequency, pulse width, duty ratio and trigger voltage are $10 \mathrm{~Hz}, 5 \mathrm{~ms}, 5 \%$, and approximately $7 \mathrm{kV}$, respectively. The substrate bias voltages are ground (GND), DC $100,-300$, and $-500 \mathrm{~V}$. The deposition time and base pressure of the chamber are $40 \mathrm{~min}$ and less than $1 \times 10^{-4} \mathrm{~Pa}$, respectively.

The arc discharge voltage and cathode wear amount were measured for deriving discharge properties. The arc discharge voltage is derived from the potential difference between the anode and cathode using an oscilloscope (Tektronix TDS2014), and the cathode wear amounts were derived by the difference between the cathode mass before and after discharge. This difference was measured using an electronic balance (Sartorius CP224s). The thickness of the W-C films and substrate temperature reached at deposition were measured for deriving deposition properties. The thickness was measured using a stylus surface profiler (Veeco Dektak 3). The W-C film surface was observed by using an optical microscope (Nikon ECLIPSE ME600) and a field emission scanning electron microscope (FE-SEM, HITACHI SU8000 Type II). The substrate temperature at deposition was measured using a thermos label, which can measure temperature of $50^{\circ} \mathrm{C}$ or more at $5{ }^{\circ} \mathrm{C}$ intervals. The film properties, bonding structure, element composition, and film density were analyzed using an X-ray diffractometer (XRD, Rigaku RINT-2500), X-ray photoemission spectroscopy (XPS, ULVAC-PHI Quantera SXM-CI), and X-ray reflectance measurement device (Phillips, X'Pert PRO MRD), respectively.

\section{Results and Discussion}

\subsection{Discharge Properties}

The relationship between the arc discharge voltage and pulse arc current at a constant bias voltage of DC-100 V was determined. When using WC-Co, the arc discharge voltages were 27,35 , and $38 \mathrm{~V}$ at pulse arc current of 50,100 , and 150 
A, respectively. On the other hand, when using WC-Ti, the arc discharge voltages were 28,41 , and $44 \mathrm{~V}$ at pulse arc current of 50, 100, and $150 \mathrm{~A}$, respectively. Evidently, the arc discharge voltage increases with increasing pulse arc current.

Figure 1 shows the relationship between the cathode wear amount and varied pulse arc currents. The cathode wear amount of the WC-Co was smaller than that of the WC-Ti, and it is considered that droplet emission from the WC-Co is less than that of the WC-Ti. The cathode wear amount at a current of $50 \mathrm{~A}$ was smaller than those at pulse arc currents of 100 and $150 \mathrm{~A}$. Based on this, the pulse arc current of $50 \mathrm{~A}$ was regarded as too low for cathode evaporation.

\subsection{Deposition Properties}

Figure 2 shows the $\mathrm{W}-\mathrm{C}$ film thickness fabricated using different pulse arc currents at a constant bias voltage of DC-100 V. At $50 \mathrm{~A}$, a very thin film, approximately $10 \mathrm{~nm}$ thick, was formed. The explanation considered for this thickness is the small amount of evaporation from the cathode. At $100 \mathrm{~A}$ or more, film thickness

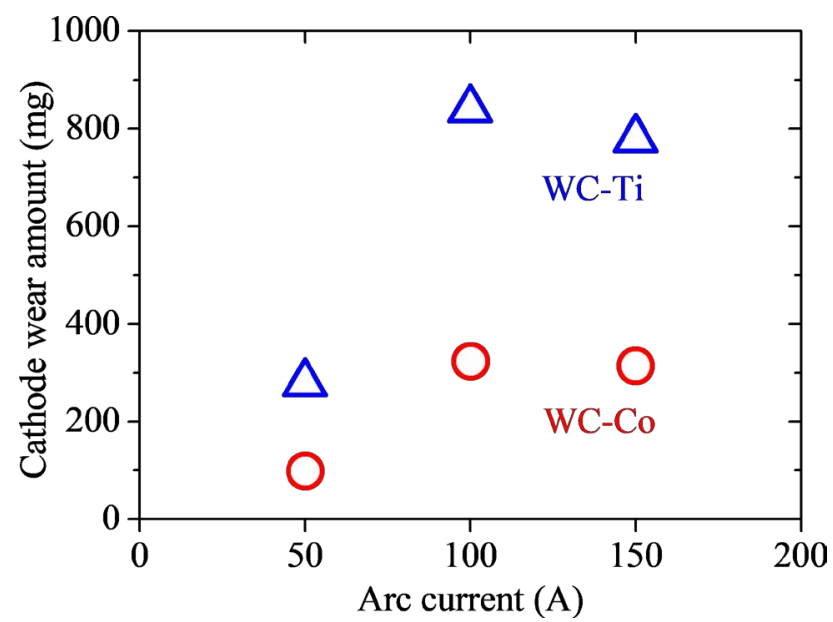

Figure 1. Cathode wear amount under different pulse arc currents at a constant bias voltage of DC-100 V.

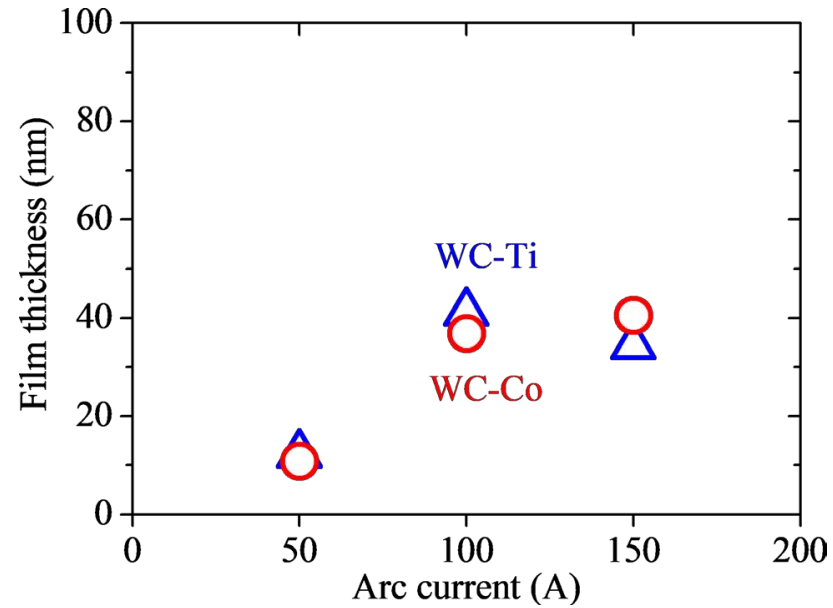

Figure 2. Film thickness of W-C films fabricated at different pulse arc currents and a constant bias voltage of DC-100 V. 
did not change and was not dependent on the cathode. Therefore, compared to WC-Ti, consumption of cathode material is suppressed in the WC-Co, indicating that the efficiency for film preparation is good in WC-Co. Moreover, the $\mathrm{W}-\mathrm{C}$ film thickness was fabricated at different bias voltages and a constant pulse arc current of $100 \mathrm{~A}$. However, a relationship which is the bias voltage and cathode type to the film thickness was not observed. The substrate temperature reached at deposition was approximately $50^{\circ} \mathrm{C}$ under each condition, and $\mathrm{W}-\mathrm{C}$ films could be formed at relatively low temperatures.

The optical micrographs of $\mathrm{W}-\mathrm{C}$ films are shown in Figure 3(a) and Figure 3(b), and the FE-SEM photomicrographs of W-C films are shown in Figure 3(c) and Figure 3(d). In these films, the arc current and bias voltage were $100 \mathrm{~A}$ and DC-100 V, respectively. The cathode material of W-C films shown in Figure 3(a) and Figure 3(c) are WC-Co, and in Figure 3(b) and Figure 3(d) are WC-Ti. As shown in Figure 3, very few droplets were observed at the surface of W-C films at the macroscopic and microscopic levels. This result means that the droplets and plasmas generated from the cathode were separated by the filter coil. Furthermore, the separated plasmas were transported to the substrate.

\subsection{Film Properties}

The structure of the $\mathrm{W}-\mathrm{C}$ films prepared under each condition was investigated by XRD analysis. The scanning angle of the detector, $2 \theta$, was varied within the range of $30^{\circ}-80^{\circ}$ in increments of $0.02^{\circ}$. Figure 4 shows the XRD spectra of $\mathrm{W}$-C films fabricated at different pulse arc currents and a constant bias voltage

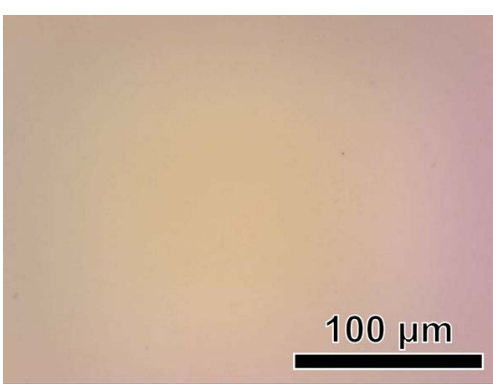

(a)

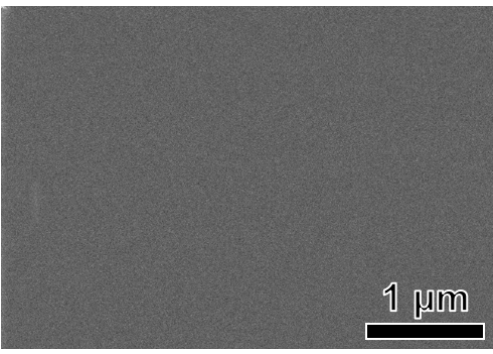

(c)

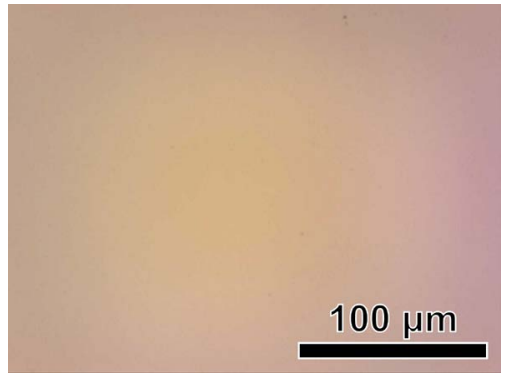

(b)

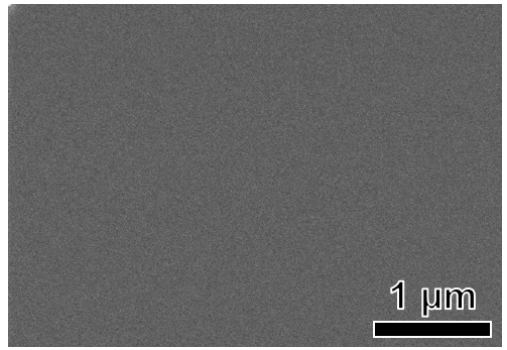

(d)

Figure 3. The optical micrographs of $\mathrm{W}-\mathrm{C}$ films fabricated at a pulse arc current of $100 \mathrm{~A}$ and bias voltage of DC-100 V by using (a) WC-Co and (b) WC-Ti. The FE-SEM photomicrographs of $\mathrm{W}-\mathrm{C}$ films fabricated at a pulse arc current of $100 \mathrm{~A}$ and bias voltage of DC-100 V by using (c) WC-Co and (d) WC-Ti. 


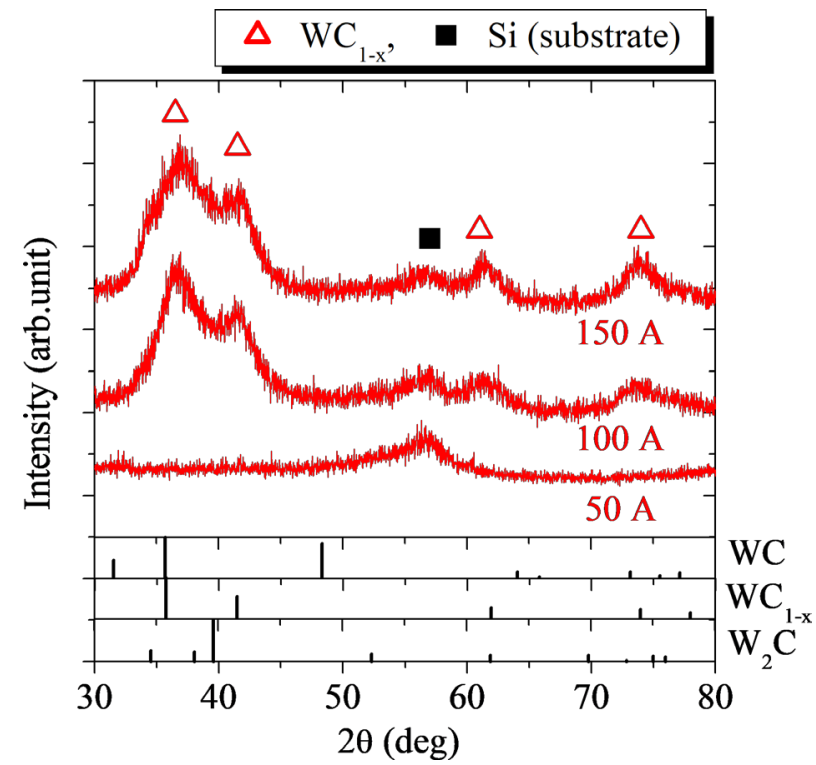

(a)

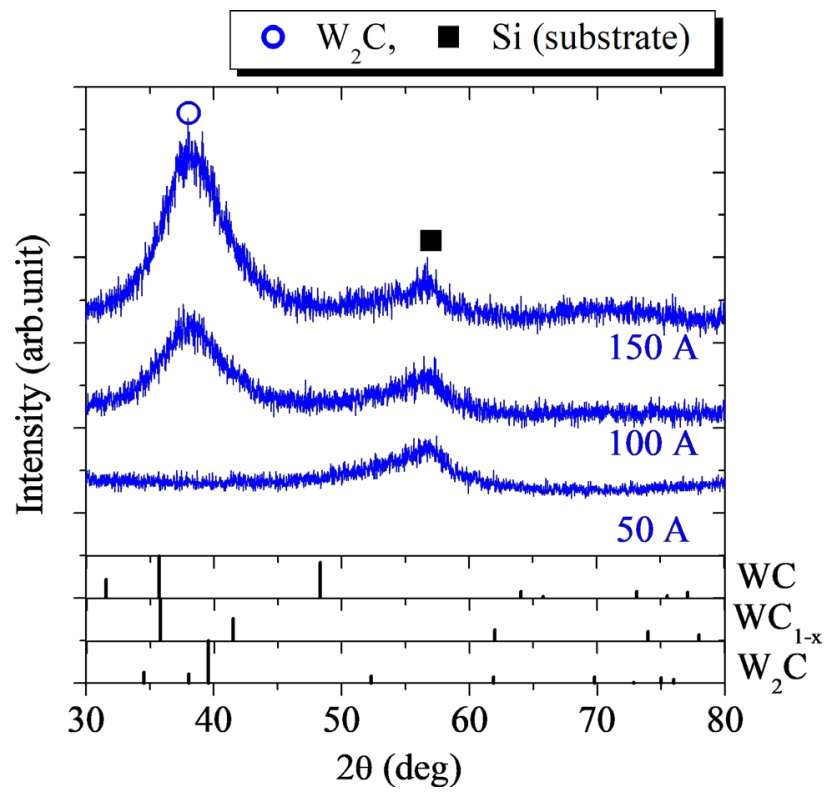

(b)

Figure 4. XRD spectra of $\mathrm{W}$-C films fabricated at different pulse arc currents and a constant bias voltage of DC-100 V using (a) WC-Co and (b) WC-Ti. The theoretical intensities of each crystal phase are shown in the lower part of the figure [14] [30] [31].

of DC-100 V. Figure 4(a) and Figure 4(b) are the spectra of films using WC-Co and WC-Ti, respectively. On the other hand, Figure 5 shows the XRD spectra of $\mathrm{W}-\mathrm{C}$ films fabricated at different bias voltages and a constant pulse arc current of 100 A. Figure 4(a) and Figure 4(b) show the spectra of films using WC-Co and WC-Ti, respectively. Relatively broad peaks are observed in Figure 4 and Figure 5 . The broad peaks are generally caused by many factors such as small crystal grain size and strain. Among these factors, small crystal grains are considered to be the primary factor. This because that the fabricated $\mathrm{W}-\mathrm{C}$ films have a 
thickness of nanometer order and the $\mathrm{W}$-C films are thought to be nanostructured. Therefore, it is considered that their broad peaks were led by nanometer-sized crystallites. There are two main peaks of approximately $36^{\circ}$ and $42^{\circ}$ as shown in Figure 4(a) and Figure 5(a), while there is a single main peak of approximately $38^{\circ}$ as shown in Figure $4(\mathrm{~b})$ and Figure $5(\mathrm{~b})$. Therefore, from the theoretical intensities [14] [30] [31] of each crystalline phase which shown in lower part of Figure 4 and Figure 5, the crystalline phase of W-C films fabricated by using WC-Co and WC-Ti were observed with the $\mathrm{W}_{2} \mathrm{C}$ and $\mathrm{WC}_{1-\mathrm{x}}$, respectively. By using different cathodes, crystalline phases could be produced.

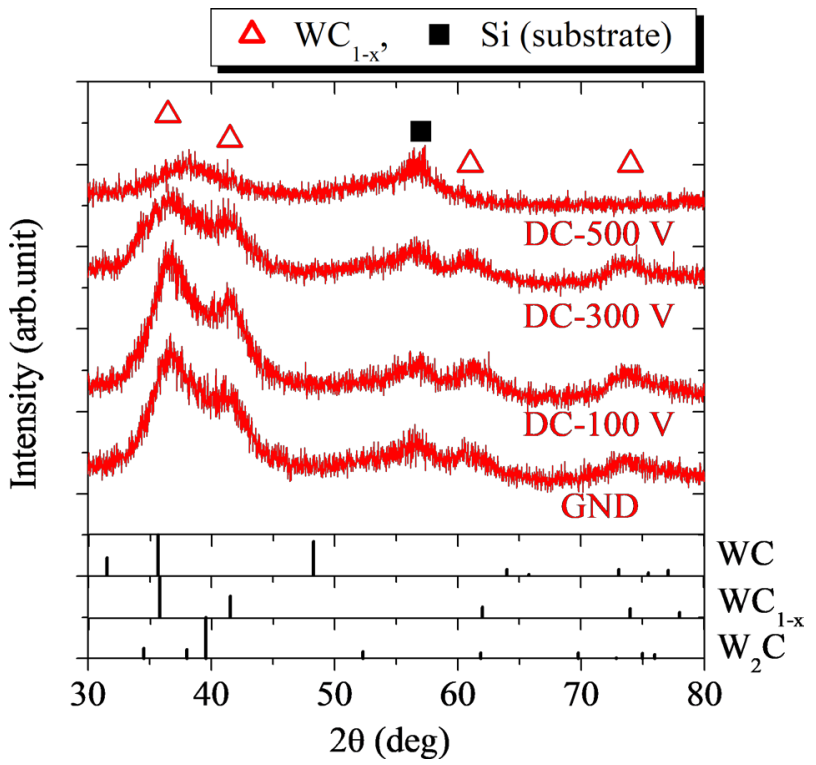

(a)

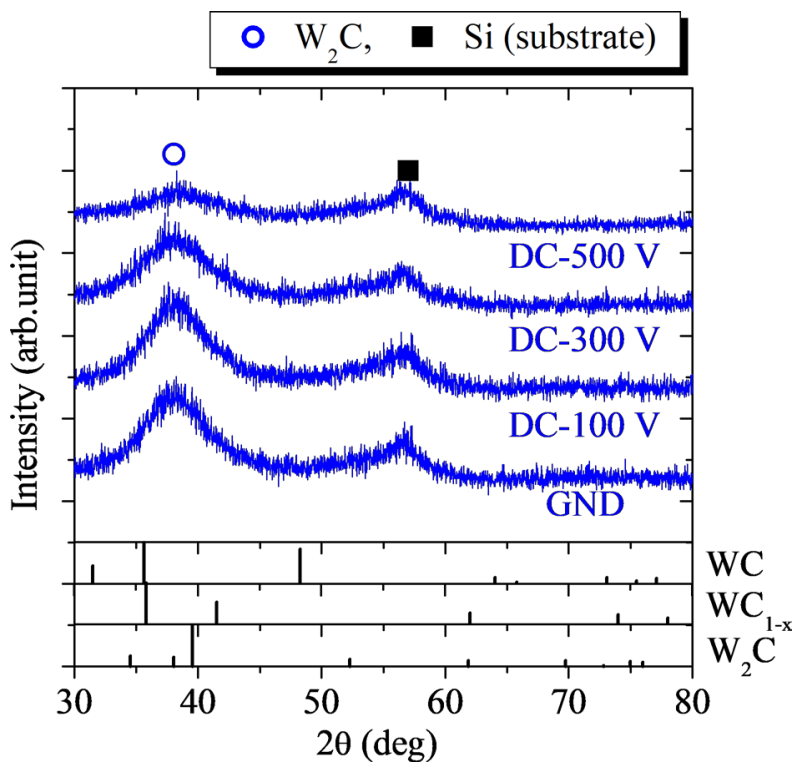

(b)

Figure 5. XRD spectra of $\mathrm{W}-\mathrm{C}$ films fabricated at different bias voltages and a constant pulse arc current of $100 \mathrm{~A}$ using (a) WC-Co and (b) WC-Ti. The theoretical intensities of each crystal phase are shown in the lower part of the figure [14] [30] [31]. 
In Figure 4, the full width at half maximum (FWHM) of the main peak decreased with increasing pulse arc current. This means that the crystallite size tends to increase with an increase in pulse arc current. Consequently, crystallinity tends to improve. Moreover, in Figure 5, the FWHM of the main peak increased with increasing bias voltage. Therefore, this also meant that the crystallite size tends to decrease with an increase in bias voltage, so crystallinity tended to worsen.

Figure 6 shows the XPS spectra of W-C films made of WC-Co at a pulse arc current and bias voltage of $100 \mathrm{~A}$ and DC-100 V, respectively. Figure 6(a) and Figure 6(b) show the C1s and W4f spectra, respectively. The lower spectra are the film surfaces, and the upper ones are the surface spectra after Ar ion sputtering, which means that the latter are the inside spectra of the films. Under the sputtering conditions, the acceleration voltage and processing time were $1 \mathrm{kV}$ and $30 \mathrm{~s}$, respectively. As shown in Figure 6(a), the film surface was $\mathrm{C}-\mathrm{C}$ rich, and only a small amount of carbon oxide was observed. As shown in Figure 6(a), after sputtering, the peak of the spectrum shifted to C-W. It is considered that $\mathrm{C}-\mathrm{C}$ was preferentially broken by the Ar ion. As shown in Figure 6(b), W-C and $\mathrm{W}-\mathrm{O}$ were observed at the film surface, which means that the carbide and oxide of the tungsten were formed. As shown in Figure 6(b), W-O peak was reduced by Ar sputtering, and oxygen was not detected by the results of the quantitative analysis. It is regarded that the oxide formed by air exposure of the sample after the fabrication exists only in the film surface. Moreover, under other conditions, the XPS spectra also exhibited a trend similar to those in Figure 6.

Figure 7 shows the C/W ratio of the W-C film surface calculated by XPS analysis. Figure 7(a) and Figure 7(b) shows the results of W-C films fabricated

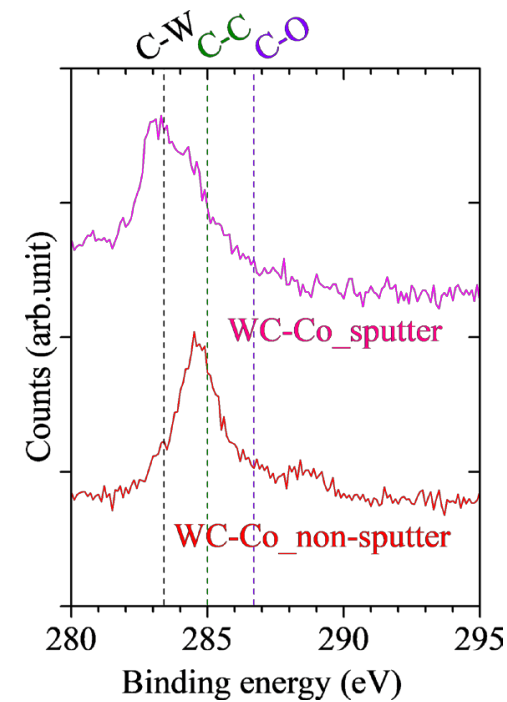

(a)

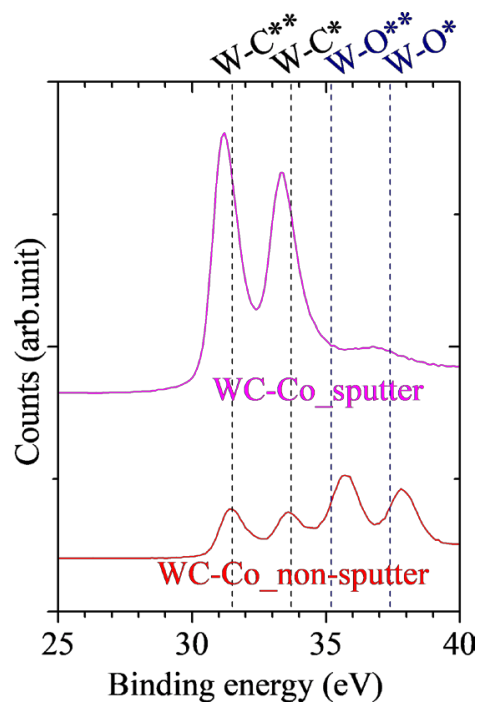

(b)

Figure 6. XPS spectra of W-C films fabricated at a pulse arc current of $100 \mathrm{~A}$ and bias voltage of DC-100 V using WC-Co. The C1s and W4f spectra are shown in (a) and (b), respectively. In the W4f spectra, ${ }^{*}$ and ${ }^{*}$ correspond to $\mathrm{W}_{4} \mathrm{f}_{5 / 2}$ and $\mathrm{W} 4 \mathrm{f}_{7 / 2}$, respectively. The theoretical binding energy of each bonding is shown by the broken vertical line [12] [15]. 


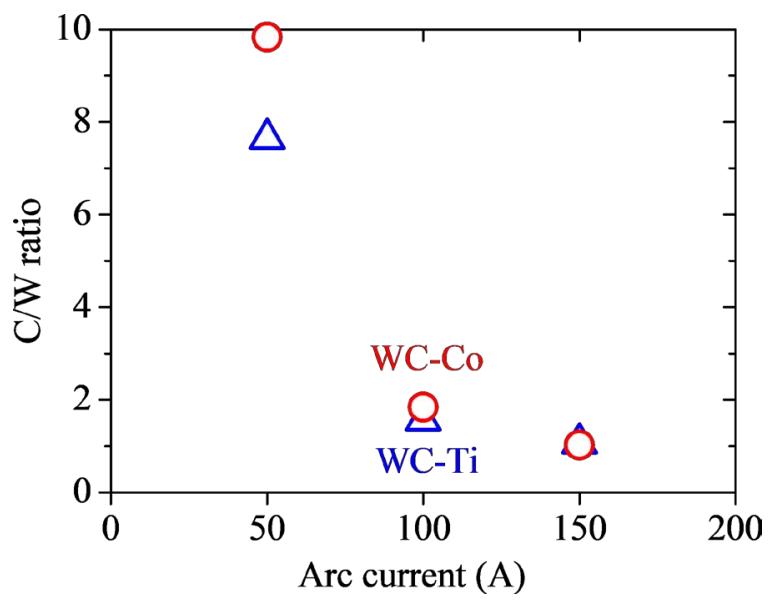

(a)

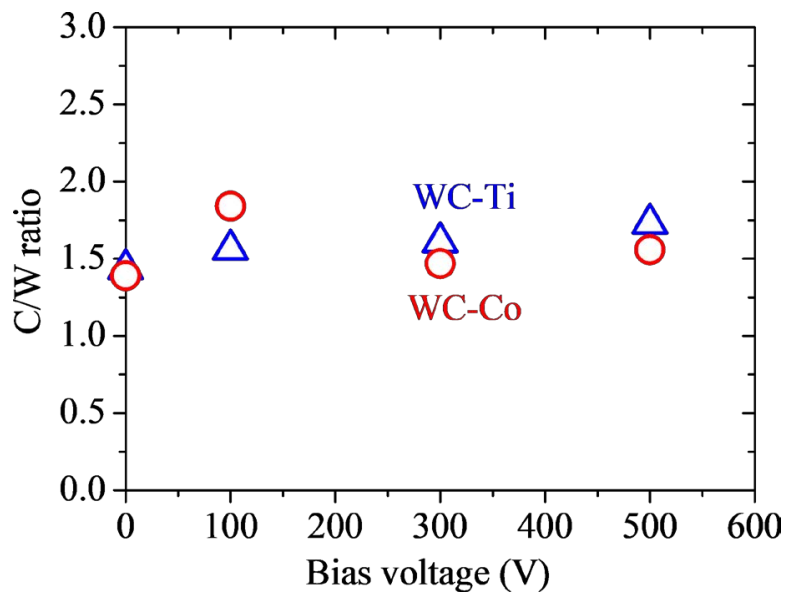

(b)

Figure 7. C/W ratio of W-C films calculated by XPS analysis, fabricated at (a) different pulse arc currents and a constant bias voltage of DC-100 V, and (b) different bias voltages and a constant pulse arc current of $100 \mathrm{~A}$.

at different pulse arc currents and a constant bias voltage of DC-100 V, and at different bias voltages and constant pulse arc current of $100 \mathrm{~A}$, respectively. As shown in Figure 7(a), the $\mathrm{C} / \mathrm{W}$ ratio decreased with increasing pulse arc current. This means that the tungsten contained within the W-C films increased with increasing pulse arc current. The relative amount of tungsten reaching the substrate was more compared to that of carbon. Therefore, $\mathrm{W}_{2} \mathrm{C}$ or $\mathrm{WC}_{1-\mathrm{x}}$ in the $\mathrm{W}-\mathrm{C}$ films increased with increasing pulse arc current, so that it is considered that crystallinity tended to improve with increasing pulse arc current, as shown in Figure 4. As shown in Figure 7(b), the C/W ratio hardly changed relative to the bias voltage. Therefore, the amount of tungsten and carbon ions reaching the substrate is not affected by the bias voltage. Although not shown in the figure, Co and $\mathrm{Ti}$ as binders were not detected in XPS analysis. Therefore, the binders contained in the cathodes were not in the fabricated films.

Figure 8 shows the $\mathrm{W}$-C film density fabricated at different pulse arc currents and bias voltages. In Figure 8(a), film density increased with increasing pulse 


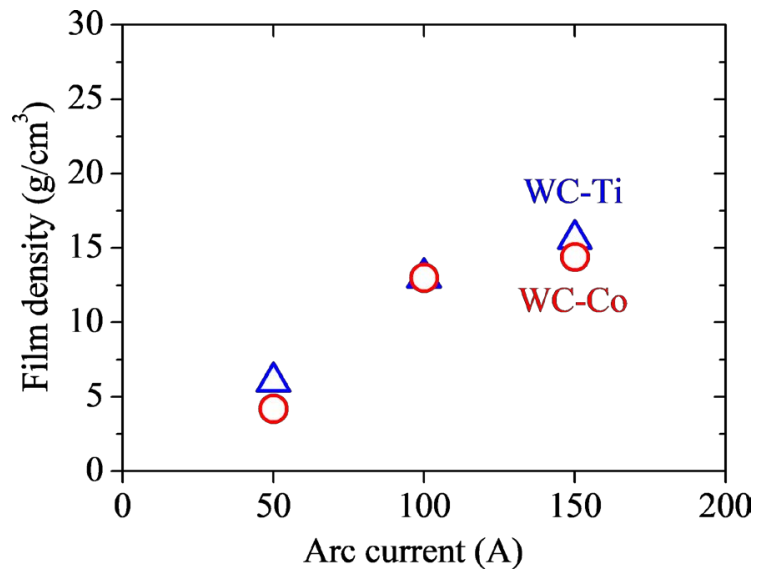

(a)

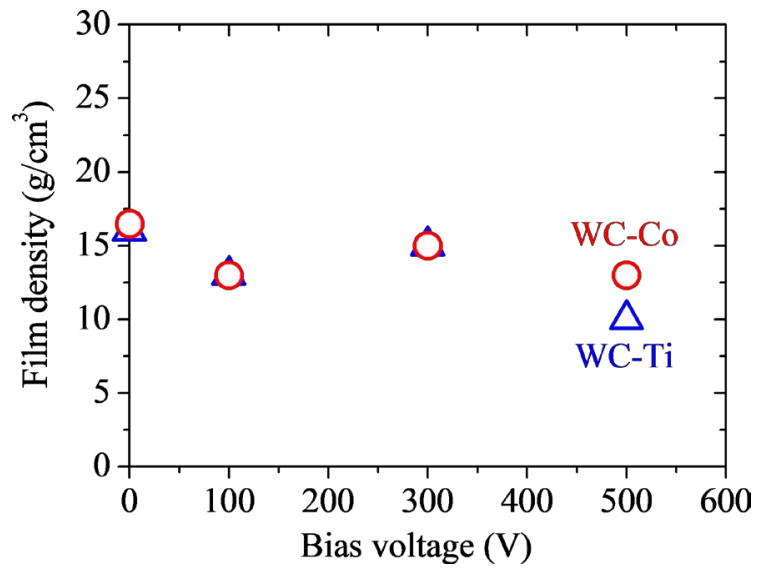

(b)

Figure 8. Film density of W-C films, fabricated at (a) different pulse arc currents and a constant bias voltage of DC-100, and (b) different bias voltages and a constant pulse arc current of $100 \mathrm{~A}$.

arc current. This tendency is thought to be due to the increased in tungsten contained within the W-C film with increasing pulse arc current, as shown in Figure 7 (a). In Figure 8(b), film density hardly changed relative to the change in bias voltage. This trend was similar to that observed in Figure $7(\mathrm{~b})$. These results indicate that the composition of the $\mathrm{W}$-C films does not depend on bias voltage.

\section{Conclusions}

The W-C films were fabricated on Si substrate by using the FPAD system. As cathode material, we used two types of WC, containing Co and Ti as binders, respectively. The substrate temperature was at a relatively low temperature of approximately $50^{\circ} \mathrm{C}$. Moreover, the fabricated W-C films had very few droplets. The crystalline phase of $\mathrm{W}_{2} \mathrm{C}$ and $\mathrm{WC}_{1-\mathrm{x}}$ were observed by using WC-Co and $\mathrm{WC}-\mathrm{Ti}$, respectively. The $\mathrm{C} / \mathrm{W}$ ratio and film density depended on the pulse arc current, regardless of the type of binders. Moreover, the tungsten contained within the W-C films increased with increasing pulse arc current. In this study, 
it was shown that the W-C films of different crystalline phases could be fabricated using different $\mathrm{WC}$ cathodes at low temperatures.

As an application of these W-C films, it could be expected to apply the W-C films to the DLC interlayer for improving the adhesion with the DLC film. Additionally, it is considered that these $\mathrm{W}-\mathrm{C}$ films fabricated at low temperature are possible to deposit to the low melting point material.

\section{Acknowledgements}

This study was supported by JSPS KAKENHI Grants-in-Aid for Scientific Research, Osawa Scientific Studies Grants Foundation, and The Foundation for Technology Promotion of Electronic Circuit Board.

\section{References}

[1] Radic, N., Grzeta, B., Milat, O., Ivkov, J. and Stubicar, M. (1998) Tungsten-Carbon Films Prepared by Reactive Sputtering from Argon-Benzene Discharges. Thin Solid Films, 320, 192-197. https://doi.org/10.1016/S0040-6090(97)00758-X

[2] Voevodin, A.A., O’Neill, J.P., Prasad, S.V. and Zabinski, J.S. (1999) Nanocrystalline WC and WC/a-C Composite Coatings Produced from Intersected Plasma Fluxes at Low Deposition Temperatures. Journal of Vacuum and Technology A, 17, 986-992. https://doi.org/10.1116/1.581674

[3] Esteve, J., Zambrano, G., Rincon, C., Martinez, E., Galindo, H. and Prieto, P. (2000) Mechanical and Tribological Properties of Tungsten Carbide Sputtered Coatings. Thin Solid Films, 373, 282-286. https://doi.org/10.1016/S0040-6090(00)01108-1

[4] Tavasanoglu, T., Begum, C., Alkan, M. and Yucel, O. (2013) Deposition and Characterization of Tungsten Carbide Thin Films by DC Magnetron Sputtering for Wear-Resistant Applications. The Journal of The Minerals, 65, 562-566.

[5] Mrabet, S.E., Abad, M.D., Lopez-Cartes, C., Martinez-Martinez, D. and SanchezLopez, J.C. (2009) Thermal Evolution of WC/C Nanostructured Coatings by Raman and In Situ XRD Analysis. Plasma Processes and Polymers, 6, S444-S449. https://doi.org/10.1002/ppap.200931004

[6] Utsumi, T., Oka, Y., Fujiwara, E. and Yatsuzuka, M. (2007) Effect of a Hard Supra-Thick Interlayer on Adhesion of DLC Film Prepared with PBIID Process. Nuclear Instruments and Methods in Physics Research B, 257, 706-709. https://doi.org/10.1016/j.nimb.2007.01.127

[7] Pujada, B.R., Tichelaar, F.D. and Janssen, G.C.A.M. (2008) Hardness of and Stress in Tungsten Carbide-Diamond Like Carbon Multilayer Coatings. Surface and Coatings Technology, 203, 562-565. https://doi.org/10.1016/j.surfcoat.2008.05.051

[8] Yatsuzuka, M., Oka, Y., Tomita, A., Murata, N. and Hirota, M. (2007) Wear Properties of DLC and Plasma Sprayed WC Structure Coating. Solid State Phenomena, 127, 245-250. https://doi.org/10.4028/www.scientific.net/SSP.127.245

[9] Hirata, A., Zheng, H. and Yoshikawa, M. (1998) Adhesion Properties of CVD Diamond Film on Binder-Less Sintered Tungsten Carbide Prepared by the Spark Sintering Process. Diamond and Related Materials, 7, 1669-1674. https://doi.org/10.1016/S0925-9635(98)00242-8

[10] Tang, X., Haubner, R., Lux, B. and Kieffer, B. (1995) Preparation of Ultrafine CVD WC Powders Deposited from $\mathrm{WCl}_{6}$ Gas Mixtures. Journal de Physique $I V, 5$, C5-1013-C5-1020. https://doi.org/10.1051/jphyscol:19955119 
[11] Nazon, J., Herbst, M., Marco de Lucas, M.C., Bourgeois, S. and Domenichini, B. (2015) WC-Based Thin Films Obtained by Reactive Radio-Frequency Magnetron Sputtering Using W target and Methane Gas. Thin Solid Films, 591, 119-125. https://doi.org/10.1016/j.tsf.2015.08.035

[12] Zellner, M.B. and Chen, J.G. (2004) Synthesis, Characterization and Surface Reactivity of Tungsten Carbide (WC) PVD Films. Surface Science, 569, 89-98. https://doi.org/10.1016/j.susc.2004.07.029

[13] Rincon, C., Zambrano, G., Carvajal, A., Prieto, P., Galindo, H., Martinez, E., Lousa, A. and Esteve, J. (2001) Tungsten Carbide/Diamond-Like Carbon Multilayer Coatings on Steel for Tribological Applications. Surface and Coatings Technology, 148, 277-283. https://doi.org/10.1016/S0257-8972(01)01360-3

[14] Abdelouahdi, K., Sant, C., Legrand-Buscema, C., Aubert, P., Perriere, J., Renou, G. and Houdy, P. (2006) Microstructural and Mechanical Investigations of Tungsten Carbide Films Deposited by Reactive RF Sputtering. Surface and Coatings Technology, 200, 6469-6473. https://doi.org/10.1016/j.surfcoat.2005.11.015

[15] Beadle, K.A., Gupta, R., Mathew, A., Chen, J.G. and Willis, B.G. (2008) Chemical Vapor Deposition of Phase-Rich WC Thin Films on Silicon and Carbon Substrates. Thin Solid Films, 516, 3847-3854. https://doi.org/10.1016/j.tsf.2007.06.170

[16] Kelly, C.M., Garg, D. and Dyer, P.N. (1992) Kinetics of Chemical Vapor Deposition of Tungsten Carbide. Thin Solid Films, 219, 103-108. https://doi.org/10.1016/0040-6090(92)90729-U

[17] Anders, A. (2002) Energetic Deposition Using Filtered Cathodic Arc Plasmas. Vacuum, 67, 673-686. https://doi.org/10.1016/S0042-207X(02)00260-9

[18] Hakovirta, M., Tiainen, V.-M. and Pekko, P. (1999) Review: Techniques for Filtering Graphite Macroparticles in the Cathodic Vacuum Arc Deposition of Tetrahedral Amorphous Carbon Films. Diamond and Related Materials, 8, 1183-1192. https://doi.org/10.1016/S0925-9635(99)00111-9

[19] Takikawa, H. and Tanoue, H. (2007) Review of Cathodic Arc Deposition for Preparing Droplet-Free Thin Films. IEEE Transactions on Plasma Science, 35, 992-999. https://doi.org/10.1109/TPS.2007.897907

[20] Buschel, M. and Grimm, W. (2001) Influence of the Pulsing of the Current of a Vacuum Arc on Rate and Droplets. Surface and Coatings Technology, 142-144, 665-668. https://doi.org/10.1016/S0257-8972(01)01254-3

[21] Martin, P.J. and Bendavid, A. (2001) Invited Review: Review of the Filtered Vacuum Arc Process and Materials Deposition. Thin Solid Films, 394, 1-15. https://doi.org/10.1016/S0040-6090(01)01169-5

[22] Boxman, R.L., Zhitomirsky, V., Alterkop, B., Gidalevich, E., Beilis, I., Keidar, M. and Goldsmith, S. (1996) Recent Progress in Filtered Vacuum Arc Deposition. Surface and Coatings Technology, 86-87, 243-253. https://doi.org/10.1016/S0257-8972(96)03023-X

[23] Leng, Y.X., Chen, J.Y., Yang, P., Sun, H., Wan, G.J. and Huang, N. (2003) Mechanical Properties and Thermomechanical Stability of Diamond-Like Carbon Films Synthesized by Pulsed Vacuum Arc Plasma Deposition. Surface and Coating Technology, 173, 67-73. https://doi.org/10.1016/S0257-8972(03)00442-0

[24] Kwok, S.C.H., Zhang, W., Wan, G.J., McKenzie, D.R., Bilek, M.M.M. and Chu, P.K. (2007) Hemocompatibility and Anti-Bacterial Properties of Silver Doped Diamond-Like Carbon Prepared by Pulsed Filtered Cathodic Vacuum Arc Deposition. Diamond and Related Materials, 16, 1353-1360.

https://doi.org/10.1016/j.diamond.2006.11.001 
[25] Chun, S.-Y. and Chayahara, A. (2000) Pulsed Vacuum Arc Deposition of Multilayers in the Nanometer Range. Surface and Coatings Technology, 132, 217-221. https://doi.org/10.1016/S0257-8972(00)00850-1

[26] Sanders, D.M. and Anders, A. (2000) Review of Cathodic Arc Deposition Technology at the Start of the New Millennium. Surface and Coatings Technology, 133-134, 78-90. https://doi.org/10.1016/S0257-8972(00)00879-3

[27] Anders, A., Pasaja, N., Lim, S.H.N., Petersen, T.C. and Keast, V.J. (2007) Plasma Biasing to Control the Growth Conditions of Diamond-Like Carbon. Surface and Coatings Technology, 201, 4628-4632. https://doi.org/10.1016/j.surfcoat.2006.09.313

[28] Anders, A. (1999) Approaches to Rid Cathodic Arc Plasmas of Macro and Nanoparticles: A Review. Surface and Coatings Technology, 120-121, 319-330. https://doi.org/10.1016/S0257-8972(99)00460-0

[29] Shi-jin, L., Banno, T., Mera, Y., Kitajima, M., Ishioka, K., Harada, Y., Kitajima, Y., Shin, S. and Maeda, K. (2008) The Role of a Graphitic Surface Layer in Electron-Stimulated Ordering in Tetrahedral Amorphous Carbon Films. New Carbon Materials, 23, 241-244. https://doi.org/10.1016/S1872-5805(08)60026-8

[30] ICDD, Card 01-089-2727.

[31] ICDD, Card 00-035-0776. 